ment, will be limited to isotopes and labelled compounds not available at Kjeller.

The work of the Physics Department was concentrated on the acquirement of a thorough theoretical understanding of the operation of the reactor and on the establishment of experimental facilities for research utilizing the neutron flux. Equipment available now includes a rotating velocity selector with spiral channels for the investigation of nuclear reaction cross-sections for thermal neutrons, a pile oscillator, a beta-spectrometer of the short-lens type with no iron core, two mass spectrometers and a tenchannel pulse-height analyser with a resolving time of about $20 \mu \mathrm{sec}$. Some preliminary discussions and investigations on new reactor types, with particular reference to ship propulsion reactors, are reported and this work is being continued. A health physicist was appointed to supervise the radiation monitoring programme, and the monitoring instruments which have been in use since the reactor started consist of permanent installations, mainly ionization chambers of the Chalk River type ; semi-permanent monitors and portable monitors of the Harwell type; and personal monitoring equipment, dosimeters and films.

The report concludes with a statement of accounts of the Joint Establishment covering the period July 1, $1951-J u n e ~ 30,1952$; a list of personnel in the various departments ; and details of the information service, together with references to the scientific articles published by members of the staff of the Establishment during the period under review.

\section{CENSUS OF WOODLANDS IN GREAT BRITAIN}

$\mathrm{A}$

MOST interesting report on the census of woodlands in Great Britain has been issued by the Forestry Commission*: The report is based on a comprehensive stocktaking, and this greatly amplifies the information published in 1951 in summary form. The present census was aarried out between January 1947 and June 1949, no fewer than 308,000 tabular reports and maps being submitted by parties of trained surveyors. In the report the methods upon which the material collected was classified are detailed. The woodlands are divided into coniferous high forest, broad-leaved high forest, cuppice and coppice with standards, scrub, devastated woods and felled woodland. The distribution of the woods will probably cause surprise to many. The counties with the largest woodland areas are: Inverness $(212,616$ acres), Yorkshire, Hampshire, Perth, Aberdeen, Sussex, Argyll, Kent and Devonshire; while Montgomery has more than any other county in Wales. All counties have some woodland-London, with 639 acres, or 0.9 per cent of its land area, is actually more densely wooded than Caithness.

The data given are separated for the Forestry Commission and private owner, respectively. The total area of woodland in Britain (excluding woodlands less than 5 acres in extent) at September 30 , 1947, was $3,448,362$ acres, or $6 \cdot 1$ per cent of the land surface of Britain, or only 71 acres of woodland to every 1,000 people. It is stated that Norway has 23.8 per cent of its land surface under trees, Belgium

* Forestry Commission. Census Report No. 1 : Census of Woodlands, 1947-1949; Woodlands of Five Acres and Over. Pp. $264+$ 11 plates. (London: H.M.S.O., 1952.) 12s. $6 d$. net.
$18 \cdot 2$ per cent, and Denmark $9 \cdot 3$ per cent. As is well known, Britain has the lowest percentages of woodland compared with its land area to be found in Western Europe, excepting Ireland and Holland. The comparison is somewhat misleading. Britain is a small island, densely populated and highly industrialized. Timber is essential to these industries; but foresters and agriculturists realize that all land which can produce crops or feed stock must be utilized by the latter. This of necessity sets the limit to the future area of woodlands ; in addition, areas for housebuilding and works have to be eliminated. In each county this matter is now under consideration between those concerned with development and extension of agricultural and forest areas.

The report states that $1,309,569$ acres of the total area of woodland were classified in the census as scrub, devastated or felled areas, largely as the result of overfelling during the two World Wars. This figure, says the report, shows the amount of rehabilitation work necessary to restock these areas. There is some difference of opinion upon one type of woodland classified by the Commission as 'scrub'. There are considerable numbers of poor coppice areas in England so classified, and it is true that the coppice is at present in a poor condition. But this is due to the fact that, when the coppice value decreased, the owners failed to continue to replace the old stools as had been done periodically in the past from the time the area had been treated as coppice.

\section{JOURNAL OF EMBRYOLOGY AND EXPERIMENTAL MORPHOLOGY}

$\mathrm{T}$ HE first part of a new quarterly journal, the Journal of Embryology and Experimental Morphology, devoted to animal morphogenesis has recently appeared*. Its object is to act as a forum for workers mainly interested in developmental processes to be found in animals at any stage of their life-history. Research work to be published in this new journal will include descriptive, experimental, chemical and physiological embryology, regeneration and healing, developmental changes involved in functional adaptation, growth, ageing, and other aspects of late morphogenesis. Studies of gametes and gametogenesis will be considered for publication, provided they are not primarily of a cytological nature; similarly, work on the physiology of reproduction will be accepted provided it does not more appropriately fall within the scope of any other specialized journal. Aspects of protozoology will also be considered which have a bearing on morphogenesis. Papers on developmental processes in plants will receive favourable consideration, too, if they in any way assist in clarifying zoological aspects of morphogenesis.

The new journal will concentrate mainly on finished pieces of research. This means that the papers published will contain sufficient data, tables and illustrations to make clear the authors' results and conclusions. Preliminary reports and theses, therefore, will not be favourably considered for publication; neither will very long papers. It is hoped, nevertheless, when space permits, to publish theoretical and review papers.

* Journal of Embryology and Experimental Morphology. (Oxford University Press, Amen House, London, E.C.4.) $£ 448$. yearly'; $25 s$ separate issue. 
Contributions may be in English, French or German.

Such a journal is to be welcomed, especially since a strong editorial board of zoologists, anatomists and embryologists has been appointed. It will no doubt relieve congestion in other journals, and will prove invaluable as a platform for discussion, especially among those scientific research workers interested in the rapidly advancing field of morphogenesisbiological, medical, veterinary, agricultural and so forth. British members of the editorial board include such authorities as M. Abercrombie, G. R. de Beer, J. D. Boyd, F. W. R. Brambell, Honor B. Fell, W. J. Hamilton, Sidnie M. Manton, P. B. Medawar, D. R. Newth, C. H. Waddington, J. Z. Young and S. Zuckerman. Other countries are represented on the board by the following: J. Brachet, A. Dalcq, J. Pasteels (Belgium); E. Fauré-Fremiet, Et. C. Wolff (France); J. Holtfreter (United States); S. Hörstadius (Sweden) ; F. E. Lehmann (Switzerland); Chr. P. Raven and M. W. Woerdeman (Holland); A. Stefanelli (Italy); S. Toivonen (Finland).

Papers in the first (March 1953) issue, which follow a foreword written by A. M. Dalcq in the form of an essay on development, are : J. Pasteels : "Les effets de la centrifugation sur la blastula et la jeune gastrula des Amphibiens. (1) Mécanisme de la formation des organes secondaires aux dépens de l'ectoblaste"; R. M. Clayton: "Distribution of Antigens in the Developing Newt Embryo"; H. V. Brøndsted : "Rate of Regeneration in Planarians after Starvation"; A. and H. V. Brøndsted: "The Acceleration of Regeneration in Starved Planarians by Ribonucleic Acid" ; Et. Wolff, K. Haffen, M. Kieny and Em. Wolff : "Essais de cultures in vitro d'organes embryonnaires en milieux synthétiques"; J. C. van de Kamer and A. J. Schuurmans : "Development and Structure of the Saccus Vasculosus of Scylliorhinus caniculus (L.)".

The editor of the Journal of Embryology and Experimental Morphogenesis is Michael Abercrombie, Department of Anatomy, University College, Gower Street, London, W.C.1, to whom all editorial communications should be sent.

\section{ATMOSPHERIC OZONE AND THE UPPER-AIR CONDITIONS}

$\mathrm{T}$ HE amount of ozone in the atmosphere is very small, amounting to a layer less than $3 \mathrm{~mm}$. thick at normal temperature and pressure. The ozone is nearly all in the stratosphere at heights between 20 and $40 \mathrm{~km}$. and is of great importance as it absorbs almost all the solar ultra-violet radiation. Dobson showed in 1929 that over Britain the total amount of ozone changed with the surface pressure distribution; the ozone amount was found to be high on the western sides of depressions and low over anticyclones. This relation did not hold everywhere, and it was suggested that the true connexion was with the state of the atmosphere at high levels rather than that near the ground.

The latest researches into the subject are clearly described by Sir Charles Normand in his 1952 presidential address to the Royal Meteorological Society, which has now been published (Quart. J. Roy. Met. Soc., 79, No. 339, $39 ;$ 1953). Observing at Oxford with the Dobson spectrophotometer, which permits observations of ozone amount to be made even when the sky is overcast with low cloud, he has found a close inverse correlation between ozone amount and the height of the $300-\mathrm{mb}$. isobaric surface, the thickness of the layer between 500 and $300 \mathrm{mb}$., and the height of the top of the troposphere-the tropopause. The connexion between them and ozone amount is very close, extending to variations taking less than a day to complete.

Besides reporting the result, Sir Charles discusses the origin. It was at one time thought that the relation between ozone and surface pressure distribution is due to horizontal motion of stratospheric air of high or low ozone content; but, though this may well be important during spring, when ozone increases from south to north, it cannot play a significant part during autumn, when there is very little latitudinal variation of ozone. Sir Charles sees the main reason for the relation between ozone amount and the meteorology of the upper troposphere in vertical motion in the stratosphere associated with rising or falling tropopause. As nearly all the ozone is in the stratosphere, it is clear that, provided formation and dissociation of ozone are sufficiently slow, convergence will bring about an increase in the total ozone content in a vertical column and divergence a decrease. Below $35 \mathrm{~km}$. the mass of ozone in a given mass of air (ozone mixing ratio) changes very slowly, and there is convergence in the stratosphere when the tropopause sinks.

Using available information on the vertical distribution of ozone, Sir Charles shows quantitatively that this explanation is reasonable. He looks forward to more accurate information in future both on the vertical and horizontal distributions of ozone which will make the result more definite. This information is expected from the observations of a network of Dobson spectrophotometers now being set up from Spitzbergen to the Azores and Spain under the auspices of the Ozone Commission of the International Union for Geodesy and Geophysics.

\section{DETERMINATION OF THE POSITION OF A RADIO STAR}

A PAPER entitled "The Determination of the Position of a Radio Star" by F. G. Smith (Mon. Not. Roy. Astro. Soc., 112, 5 ; 1952), describing work carried out as part of a programme of the radio research at the Cavendish Laboratory, Cambridge, gives a description of a number of new methods of using the spaced-aerial interferometer and compares their accuracies with those of older methods. Four of the possible methods are dealt with-the periodicity interferometer, the crossed-axis interferometer, the variable-axis interferometer and the double-transit interferometer-and each of these is examined in turn.

It is pointed out that the new methods are particularly applicable to the accurate determinations of the positions of intense radio stars; when the object of the observations is to detect the largest possible number of radio stars, the periodicity interferometer has advantages for declinations greater than about $30^{\circ}$, while the crossed-axis interferometer has advantages at lower declinations. Appreciable refraction may occur at radio wave-lengths in the troposphere and also in the ionosphere ; in the former the refraction makes the star appear nearer the zenith than it actually is, and as the refractive index of dry air is practically the same for radio waves as 